\title{
Personality disorders diagnosis, causes, and treatments
}

\author{
Sura Sanem Köse ${ }^{1}$ D, Oytun Erbaş ${ }^{1,2}$ (D) \\ ${ }^{1}$ Institute of Experimental Medicine, Gebze-Kocaeli, Turkey \\ ${ }^{2}$ Department of Physiology, Medical Faculty of Demiroğlu Bilim University, Istanbul, Turkey
}

\begin{abstract}
Symptoms such as personality disorder, adaptation to the environment, functionality problems, and tension-anxiety can be observed. It is a set of physical, intellectual, and mental characteristics defined as thinking, functioning, and behavioral disorders. It is also defined as a mental problem based on the observation of long-term adaptation problems and strict tendencies. A wide range of factors from genetics to environment plays a role in the development of personality disorders. Although personality disorders have been studied extensively in recent years, the main causes and treatments have not been clearly understood, yet. In this review, we discuss symptoms of personality disorders together with biologicalenvironmental causes and treatments.

Keywords: Diagnosis, personality disorder, treatment.
\end{abstract}

Personality disorders is a definition used for the common physical, mental and spiritual characteristics. ${ }^{[1]}$ In the Diagnostic and Statistical Manual of Mental Disorders-IV (DSM-IV) by the American Psychiatric Association (APA) classification system for mental disorders, personality disorder defined as, long-term adjustment disorder and strict disposition manifested by individual distress or socialoccupational functional disorder. ${ }^{[2]}$ Individuals with personality disorders have problems in their relationships with their environment and have high probability of attempting suicide and selfharm and harm to their surroundings. Therefore, personality disorders also cause deaths at an early age. ${ }^{[1]}$

Personality disorders are classified as clusters $\mathrm{A}, \mathrm{B}$, and $\mathrm{C}$. Cluster $\mathrm{A}$ is characterized by strange and eccentric personalities and includes paranoid, schizoid, and schizotypal personality disorders. Personality disorders in this cluster are evaluated within the schizophrenia spectrum. Cluster B is characterized by personalities that are dramatically emotional and changeable; antisocial, borderline, histrionic and narcissistic personality disorders are included in this cluster. Cluster $C$ personality disorders are characterized by anxious and fearful personalities; withdrawn, addicted, and obsessivecompulsive personality disorders (OCPD) included in cluster $C .^{[3]}$

The reason for these behavioral disorders investigated in the same or different clusters is that they are characterized by similar and/or dissimilar personalities. However, separate examination provides more precise results for the causes, symptoms, and treatments.

\section{PARANOID PERSONALITY DISORDER}

In psychiatric disease classifications, paranoid personality disorder is defined as concepts of suspicious, unforgiving, jealous, anxious, and ruminative. ${ }^{[4,5]}$ The main feature is the distrust of others' motives. Paranoid individuals think that others have malicious intentions, such as

Correspondence: Sura Sanem Köse. Marmara Araştırma Merkezi, Deneysel Tıp Enstitüsü, TÜBiTAK Gebze Yerleşkesi Marmara Araştırma Merkezi 41470 Gebze Kocaeli, Türkiye. 
harming or deceiving them even without an objective evidence. In general, they do not share much information to others about themselves, as they fear that everything they say would be used against them. ${ }^{[6]}$ Although there are numbers of articles about paranoid personality disorder in clinical and psychodynamic terms, there is a few number of experimental data about the causes of this disorder. ${ }^{[7]}$

In particular, there are limited data about hereditary effects. However, in some studies, the rs850807 gene is related to the single nucleotide polymorphism; in other words, rs850807 is predicted to exhibit lower expression or activity in the linked paternally expressed MAGEL 2 gene (MAGE Family Member L2), the necdin gene (NDN) or both genes in individuals with high paranoia genotypes. More generally, variation in imprinted genes expressed by the brain can mediate a number of psychological human characteristics related to mentalistic cognition. ${ }^{[8]}$

As a result of studies conducted with schizophrenic subjects and control groups revealed that paranoid personality disorder is more common in relatives of schizophrenic subjects compared to control groups. ${ }^{[9]}$ Paranoid personality disorder features are observed in 30\% of family members of schizophrenic individuals. ${ }^{[10]}$

In general, cluster A personality disorders are assumed to be associated with schizophrenia for a long while, ${ }^{[11]}$ but according to data, the relationship between schizotypal personality disorder and schizophrenia is stronger than paranoid personality disorder. ${ }^{[12]}$

In addition, the demographic characteristics of paranoid personality disorder previously examined show that social factors are important risk factors. Childhood trauma plays a role in the development of paranoid personality disorder. ${ }^{[13]}$ Being rejected by parents at a very early age is believed to be a cause of paranoid personality disorder. ${ }^{[6]}$ Previous brain trauma is also a risk factor for paranoia. ${ }^{[14]}$

In another study revealed that corticotropinreleasing hormone $(\mathrm{CRH})$ levels in the cerebrospinal fluid of normal adults (control groups) with and without paranoid personality disorder were inversely proportional to the positive parent-child relationship in childhood. In this example, paranoid personality disorder has been associated with high $\mathrm{CRH}$ concentration. ${ }^{[5]}$

Regarding the individuals with paranoid personality disorder do not participate in research and due to their insecurity and unwillingness, information on treatment methods remain limited. ${ }^{[16]}$ The subjective lack felt by such individuals, does not motivate them to seek relief from treatment. The most effective treatment method is a supportive therapy method aimed at gaining the individual's trust. This therapy should focus on the empathic reflection of individual's experience of the world as a threatening environment. Since the therapist confirms the patient's feelings of hostility and alertness, the patient can feel safe enough to gradually reach the underlying feelings such as fear, rejection, and loneliness. ${ }^{[6]}$ Therefore, more studies and data collection are required on methods that can be used in the treatment of paranoid personality disorder.

\section{SCHIZOID PERSONALITY DISORDER}

It is a personality disorder observed in less than $1 \%$ of the general population. ${ }^{[17]}$ It is characterized by the lack of relationships with individuals and the lack of search for these relationships.

Individuals with schizoid personality disorder organize their lives in such a way that human relationships are limited, and they prefer professions that require less sociality. ${ }^{[18]}$ They rarely experience strong feelings and there is little or no desire for sexual activity with a partner. ${ }^{[19]}$ The number of activities they enjoy is very limited. They are unresponsive to the praise and criticism of their environment. When they are in an interpersonal environment, they express their emotions in a limited way. ${ }^{[20]}$

As is known, parents' abuse of their children has a strong, permanent and negative effect on their social, emotional, cognitive and moral development. Regarding some studies, wrongful parental behaviors such as verbal abuse, harsh punishment or indifference are among the risk factors that cause schizoid personality disorder symptoms between the ages of 22 and 33. ${ }^{21]}$ However, certain genetic reasons have not been identified as a result of the studies. Specific anatomical abnormalities (localized brain lobe 
legions) and biochemical or neurotransmitterrelated diseases have been suggested in the literature to play a role in the development of this disorder; however, at this point they are completely speculative. ${ }^{[19]}$

Koponen et al. ${ }^{[22]}$ evaluated the occurrence of psychiatric disorders in patients who experienced traumatic brain injury over a 30-year period and found that $6.7 \%$ developed schizoid personality disorder; however, they did not discuss which lesions were associated with schizoid development. Nonetheless, the lesions in the frontal lobe, limbic system and parietal lobes are most likely to be associated with persistent social-emotional inadequacies, social interaction and attachment problems, loneliness, and subsequent schizoid development. ${ }^{[23]}$

There should be no rush for diagnosing schizoid personality disorder. Different disorders can manifest the similar symptoms as personality disorders. Therefore, it is necessary to observe the patient for a long time to confirm the diagnosis and mind that cultural differences that can be seen as the signs of personality disorder. However, there is no approved treatment for schizoid personality disorder and some studies suggest that psychotherapy can help improve the recurring nature of this disorder.

Further studies are needed to obtain data about the treatments that can be applied. Moreover, schizoid patients may lead to misdiagnosis by making the therapists believe in situations that they believe or are not true. ${ }^{[24]}$ Accordingly, the clinician should encourage the patient to apply new behaviors to counter maladaptive impulses, but unfortunately, schizoid personality disorder has been overlooked compared to other personality disorders and hence treatment options are inadequate, and it has not been sufficiently emphasized. ${ }^{[20]}$

\section{SCHIZOTYPAL PERSONALITY DISORDER}

Schizotypal personality disorder is characterized by sudden discomfort from intimate relationships, decreased ability to go into close relationships, social or interpersonal inadequacies, as well as cognitive or perceptual distortions and unusual behaviors. ${ }^{[25]}$
Schizotypal personality disorder is also included in the schizophrenia spectrum. ${ }^{[26]}$ In the investigation of schizophrenia, the concept of schizotypy is important in that it includes dimensions reflecting different aspects of psychosis and allows understanding patterns in individuals who are not at risk. ${ }^{[27]}$

Recently, studies have been conducted to examine the similarities and differences between schizotypal personality disorder and autism. ${ }^{26]}$ When the classifications are examined, it is seen that disability in social functionality is considered as a common area for both disorders. In addition, there are differences between schizotypal personality disorder and autism symptoms. When the social skills domain is examined, social anxiety associated with paranoid fears is included in the criteria of schizotypal personality disorder. There is no such criterion in autism; There is a stereotypical, repetitive and stereotyped pattern in behavior, interests, and activities. ${ }^{[28]}$

Studies have shown that high schizotypy and schizotypal personality disorder and schizophrenia are genetically predisposed to each other. In recent studies, schizotypal personality disorder has been reported with a rate of 18 to $48 \%$ in children of mothers diagnosed with schizophrenia. ${ }^{[29]}$ In addition, factors such as childhood traumas and parental neglect are reported to be a risk factor for schizotypy, particularly interpersonal sensitivity dimension. ${ }^{[30]}$

Studies have investigated the RhoGAP (p250GAP gene) polymorphism that interacts with a glutamate N-methyl-D aspartate (NMDA) receptor, and it has been reported that the p250GAP gene polymorphism may play a role in susceptibility to both schizophrenia and schizotypal personality traits. ${ }^{[31]}$

The treatments are mostly applied to reduce the symptoms and increase the social functionality of the individual. Psychotherapy approaches include individual and group psychotherapies and social skills training. ${ }^{[32]}$ In addition, antidepressants are effective in obsessive-compulsive symptoms and depressive symptoms accompanying schizotypal personality disorder. ${ }^{[33]}$ No definitively beneficial treatment has yet been found, but psychotherapy and psychopharmacological approaches hold promise for schizotypal personality disorder. ${ }^{[32]}$ 


\section{ANTISOCIAL PERSONALITY DISORDER}

Antisocial personality disorder is characterized by traits such as irritability, aggression, noncompliance with social norms, and deceit. Antisocial individuals do not care about their own safety or the individuals around them; they display irresponsible behavior. They do not regret the things they did or the behaviors they displayed. ${ }^{[34]}$

Antisocial individuals have poor empathy skills. They see themselves as lonely, autonomous and powerful. Some antisocial individuals make themselves believe that they are socially excluded and mistreated by the community. They either think of individuals as exploitative or characterize them as weak and vulnerable. ${ }^{[35]}$ In some studies, it has been concluded that a complex interaction between biological (genetic/physiological/ neurobiological) and environmental factors causes the development and maintenance of antisocial personality disorder. ${ }^{[36]}$

In addition, to be diagnosed with antisocial personality disorder, an individual must be over 18 years old and have started showing the symptoms of the disease before the age of 15. ${ }^{[34]}$ Environmental factors influence a large proportion of the total variance; however, it is very difficult to determine whether the behavior is caused by genetic or environmental influences, and to what extent. If one or both parents are antisocial, it is likely that genetic risk factors for antisocial behavior are transmitted to the child. Therefore, it is difficult to determine how effective the environmental influences associated with having an antisocial parent are. A child with an antisocial parent may be more likely to be maltreated and subject to domestic violence. Data obtained from an epidemiological study show that children who witness violence from the immediate environment in childhood increase the risk of showing antisocial personality disorder symptoms in adulthood. ${ }^{[37]}$

The environment can affect how genes are or are expressed. Depending on environmental influences, brain functions may be affected by changing hormone and neurotransmitter levels. Environmental factors can have a significant impact on biological systems in the early stages of life. Recent neuroimaging studies also support this idea. ${ }^{[38]}$
In functional magnetic resonance imaging studies, ${ }^{[39]}$ functional neurobiological differences related to processing memory in the prefrontal region were detected in antisocial males who are prone to violence compared to healthy controls. In a study conducted in Germany, ${ }^{[40]}$ abnormal situations were found in the orbitofrontal cortex and ventromedial prefrontal cortex associated with emotional regulation and gray matter in the temporal lobe associated with reactive aggression in individuals with antisocial personality disorder.

Genetically, tryptophan hydroxylase 1-2 (TPH1 and TPH2) and nitric oxide/NO synthetase (NOS1) genes are known to play a role in impulsivity and aggression. In other studies, polymorphisms were found in some parts of the monoamine oxidase A (Mao-A) gene. Based on this, researchers predict that the Mao-A genotype has a regulatory effect on the development of violence and antisocial behaviors in adulthood, as well as abuse experienced at an early age. ${ }^{[41]}$ In addition, polymorphisms seen on the $G$ protein associated with the serotonin receptor 5HTR1A gene have also been associated with impulsivity. ${ }^{[42]}$ It was observed that serotonin metabolites decreased in the cerebrospinal fluid of antisocial individuals, and homovanillic acid, the metabolite of dopamine, increased. ${ }^{[43]}$

Although genes are thought to affect a small part of the total variance in antisocial behavior, identification of risk-posing genes can contribute to the development of treatment methods that can be adapted to the risk factors of the individual; thus, knowledge about biological factors that cause antisocial behavior can be expanded. ${ }^{[36]}$

The situations related to the treatment process of antisocial personality disorder are not very pleasant. Antisocial individuals rarely receive treatment. Conformity between patients and therapists is difficult. The effect of other psychopathological forms on antisocial personality disorder also makes treatment difficult. Therefore, no definite result has been obtained regarding the treatment of antisocial individuals. However, it was found that antisocial individuals who received cognitive behavioral therapy showed a slight improvement in social functioning and physical aggression, but no improvement in anger or verbal aggression compared to normal individuals who received treatment. Another form 
of treatment that has emerged in the last decade is mentalization-based therapy. This method is the capacity to think about one's own mental state and the mental states of others. This form of treatment was originally developed for individuals with borderline personality disorder. However, studies suggest that this treatment may be effective in reducing the aggressive behaviors of antisocial individuals with moderate psychopathic characteristics. ${ }^{[44,45]}$

\section{BORDERLINE PERSONALITY DISORDER}

Borderline personality disorder is characterized by a common pattern of instability in interpersonal relationships, identity, impulsivity, and mood. ${ }^{[2]}$ It has been reported that patients with borderline personality disorder are exposed to events such as trauma and neglection in childhood more compared to other patients. ${ }^{[4]}$ In addition, the interaction between genetic and environmental factors is thought to cause borderline personality disorder.

Studies on twins showed a 35\% compliance rate in monozygotic twins and $7 \%$ in dizygotic twins; this proves that there is a strong genetic effect in the development of borderline personality disorder. ${ }^{[47]}$ Genetic transmission can be effective up to $40 \%$ in borderline personality disorder. In addition, it is thought that genetic sensitivity and serotonergic dysfunction due to the TPH1 (tryptophan hydroxylase 1) gene may increase the risk of borderline personality disorder. ${ }^{[48]}$ Rinne et al. ${ }^{[49]}$ performed $\mathrm{CRH}$ tests on 39 females with borderline personality disorder and compared them with 11 healthy subjects. Twenty four of these females were found to have been constantly abused during their childhood. It was observed that the ACTH (Adrenocorticotropic Hormone) and cortisol results in the $\mathrm{CRH}$ test of chronically abused patients with borderline personality disorder were significantly higher than those who were not abused. Based on this, it can be stated that chronic abuse in childhood increases the sensitivity of $\mathrm{CRH}$ receptors.

Neurobiological imaging revealed findings such as decreased gray matter in some parts of the cortex, increased amygdala activity, and disruption of the connection between the prefrontal cortex and the amygdala. There is an increase in amygdala activity in borderline individuals. Amygdala activities are thought to be important for understanding the affective disorder of borderline individuals. ${ }^{\text {[50] }}$

Individuals with borderline personality disorder have a high rate of self-mutilation and suicide attempts. Unfortunately, there is no treatment available to prevent suicide attempts. At the same time, hospitalization does not yield positive results. ${ }^{[1]}$ Dialectical behavior therapy, transference-focused psychotherapy, schema therapy, and cognitive analytical therapy can be applied in the treatment of borderline personality disorder. ${ }^{[48]}$ Currently, the most evidence-based treatment modalities are specifically designed psychotherapies. ${ }^{[50]}$

\section{HISTRIONIC PERSONALITY DISORDER}

Histrionic personality disorder is also known as dramatic personality disorder. Histrionic individuals show themselves with their exaggerated sensuality and trying to attract attention; ${ }^{[52]}$ they often display flirtatious, seductive, charming, manipulative and lively behaviors. Their lack of attention bothers them. ${ }^{[53]}$

The methods of parenting can trigger the risk of histrionic personality disorder in children. Since histrionic personality disorder is distributed in the family, it is thought that this disorder is inherited genetically. ${ }^{[54]}$ As in all psychiatric disorders, the prevalence of personality disorders, psychiatric illnesses or substance use in the family is also a risk factor for histrionic personality disorder. ${ }^{[55]}$ In addition, there is no explicit information about the neurobiological causes of histrionic personality disorder yet.

The prevalence of histrionic personality disorder in the general population is approximately 2 to $3 \%$. Females are four times more likely to be diagnosed with histrionic personality disorder than males, but males may be more reluctant to report their symptoms and therefore remain undiagnosed. ${ }^{[56]}$

Psychotherapy is the most preferred treatment method for histrionic personality disorder. Psychodynamic psychotherapy (also known as insight-oriented therapy) is known to have successful results in treating patients with 
histrionic personality disorder. Psychodynamic psychotherapy aims to resolve underlying unconscious conflicts so that patients can better understand themselves and their behavior. ${ }^{[54]}$ As this approach has been found to be encouraging, reassuring, and non-threatening: supportive psychotherapy is a recommended treatment for patients with histrionic personality disorder. ${ }^{[53]}$ At the present time, studies on the causes and treatments of this disorder are proceeding.

\section{NARCISSISTIC PERSONALITY DISORDER}

Narcissistic individuals care excessively about themselves and they believe they are special and unique. They exaggerate their achievements and abilities. They use others to achieve their personal goals. They lack the ability to empathize and don't care about the feelings and needs of others. They display arrogant behavior and attitude. ${ }^{[57]}$

It is easy to fall in love with a narcissist. Their charm, talents, achievements, beauty, charisma, dazzling conversation, and even seemingly attention to others are fascinating. Individuals feel alive by their energies and attracted to them.

Two reasons can be shown for the development of narcissistic personalities. First, the child seeks love and attention with the inattentiveness of the parents; finds the remedy by loving himself. The second reason is that the parents overestimate the child, constantly praise or think that the child has special abilities. Both parental behaviors are key factors in predicting both overt and covert narcissism. ${ }^{[58]}$ Overt narcissism can be defined by individuals who are arrogant, selfish, and dislike to be limited. Covert narcissism, on the other hand, defines individuals who internalize comments and criticism from others and try to cope with feelings of inferiority.

A study of twins revealed interesting results about narcissistic personality disorder. In 483 twin matches, it was found that 45\% of narcissism was inherited. ${ }^{[59]}$ Further studies have not yet been conclusive, but conducting these studies would help us to gain important data about the biological origin of narcissistic personality disorder. Therefore, more research needed to obtain more information about the neuropsychological and genetic origins of narcissistic personality disorder.
A flexible treatment approach according to patient's functioning, motivation and degree of self-awareness is recommended. Psychoanalytic and psychodynamic therapy are the most common treatment methods. ${ }^{[60]}$ There are various treatment approaches specifically adopted for pathological narcissistic individuals, however, no treatment method has been proven to be effective or safe up to date.

\section{AVOIDANT PERSONALITY DISORDER}

Individuals with avoidant personality disorder are susceptible to negative reviews. They are quiet and shy. They avoid new activities and intimate relationships. Therefore, they encounter many negativities in their professional or educational life. Usually, avoidant personality disorder is confused with social phobia, but individuals with social phobia have no fear of being criticized and rejected, unlike shy individuals. However, the concept of timidity is associated with the fear of humiliation or rejection. ${ }^{[61]}$

Although the etiological data on avoidant personality disorder is limited, current studies emphasize that genetic and personal factors should be considered. According to a study conducted on twins, ${ }^{[62]}$ it is estimated that $64 \%$ of the symptoms of avoidant personality disorder are hereditary.

Genetic studies have identified a polymorphism in the dopamine D3 and D4 receptor genes (DRD3 and DRD4) associated with avoidant personality disorder symptoms. ${ }^{[63]}$ To manifest a general approach, it has been concluded that some polymorphisms in the genes that regulate the functioning of serotonin and dopaminergic systems are effective in inheriting the avoidant personality disorder, but not sufficient studies have been performed. More studies are needed to better conceptualize this personality disorder, and the interactions between gene and environment need to be further investigated. In addition, environmental factors also affect the preservation of the stability of avoidant personality disorder.

An additional study has shown that avoidant personality disorder and seasonal affective disorder (SAD) are seen in the same family. It has been found that families of individuals with $\mathrm{SAD}$ are three to four-times more likely to have 
avoidant personality disorder cases, indicating that the two disorders are etiologically related; they are different expressions of the same genetic factor. ${ }^{[64]}$

Avoidant personality disorder is a disorder that causes disruption in social functioning. As with most personality disorders, the treatment option for avoidant personality disorder is psychotherapy. Although a partial improvement was observed with some treatments applied on the patients, it was concluded that there was no definitive treatment for this disorder. Numerous studies should be conducted with different treatment methods. ${ }^{[65]}$

\section{DEPENDENT PERSONALITY DISORDER}

For individuals with dependent personality disorder, even making everyday decisions is difficult. They want other individuals to be responsible for them. Even on an issue they do not agree on, they may pretend to agree, as otherwise they think they would not get support. It is very challenging for them to start a business alone, as they lack self-confidence; they think they cannot work on their own. They think they need the advice and help of others, so they are very afraid of being left alone. When a relationship ends, they start another relationship soon after. ${ }^{[28]}$

Children of authoritarian parents can be dependent personalities. The reason for this is that this parenting style prevents children from learning through trial and error. This situation prevents children from developing their sense of autonomy and self-efficacy. In addition, overprotective parenting can lead to high levels of dependency. Similar to authoritarian parenting, overprotective parenting causes children to believe they cannot work on their own without the help, guidance, and support of others. ${ }^{[66]}$

For depended individuals, there are variety of treatment approaches, but limited controlled treatments have resulted. Cognitive behavioral therapy can be used to increase the autonomy and self-efficacy of the dependent individual. Drugs can also be supplemented during the treatment, but great care should be taken during this process. ${ }^{[67]}$ Patients may consider using drugs other than undesirable conditions, so they should be kept under control. Instead of applying additional methods to existing treatments, long-term psychodynamic therapy provides a better transition and can be used to support emotional development, but this period can take at least three or more years.

\section{OBSESSIVE-COMPULSIVE PERSONALITY DISORDERS}

Obsessive-compulsive personality disorder is also defined as an anxiety disorder. It has two main parts: obsessions and compulsions. Obsessions are unwanted thoughts, images, urges, or doubts that recur in the mind; these negatively affect communication with others and work life. Compulsions are repetitive activities that are thought to be done. This can be like checking over and over to make sure a door is locked, or repeating a certain phrase in the head to prevent harm to a loved one. The purpose of a compulsion is to deal with the distress caused by obsessive thoughts and to alleviate the anxiety that felt. However, the process of repeating these obsessions is often stressful, and the relief felt afterwards is short-lived. ${ }^{[68]}$

Studies have shown that OCD is associated with the polymorphisms of the serotonin system, 5 HTTLPR (also known as SLC6A4) and HTR2A (5-hydroxytryptamine serotonin receptor 2A) genes. In addition, variants in the COMT (catechol-O-methyltransferase) and Mao-A (monoamine oxidase A) genes are associated with OCD only in males. In addition, polymorphisms in the DAT1 (also known as SLC6A3) and DRD3 (dopamine receptor D3) genes associated with the dopamine system and the SLC1A1 gene associated with the glutamate system are also thought to cause OCD. ${ }^{[69]}$ Ongoing studies have focused on serotonin, dopamine and glutamate neurotransmitters.

In one of the largest studies, 966 individuals from 219 families were examined. In data, the 1q, 3q, 6q, 7p and 15q chromosome regions are considered to be risk regions. Evidence has been obtained that the largest risk region is $3 \mathrm{q} 27-28 .{ }^{.70]}$

At the same time, genetic factors and the relationships of different parts of the brain with OCD were examined, but no definitive conclusion was obtained. Also, biological studies could not 
give clear results as to why this condition is different in every person. For example, one person may develop an obsession with contamination while another may develop an obsession with do harm. In addition, some experts have noted that children suddenly develop OCD symptoms after suffering streptococcal infections, but there are still no clear data on why they occur.

At the treatment process, cognitive behavioral therapy is a treatment that aims to identify the connections between thoughts, emotions and behaviors. It aims to help develop practical skills to manage negative thinking or behavioral patterns that can lead to difficulties. Treatment can be applied individually or in groups, and there is important evidence that this method is particularly effective in combating OCD. Some individuals find medication for OCD helpful in combination with speech-based treatments such as cognitive behavioral therapy, but the recommended medications can have side effects such as nausea, headache, sleep disturbance, gastric problems and increased anxiety and can also cause sexual disturbances. If severe anxiety is experienced in addition to OCD, sedatives such as diazepam can be used, but these drugs should be used for short-term treatments, as they have a risk of addiction and may have side effects such as drowsiness, confusion, instability, and nausea. ${ }^{[68]}$

In conclusion, personality disorders are characteristics that negatively affect individuals social and professional life. At the general population, they manifest a wide distribution. Individuals with personality disorders are unaware of their impairments, often displaying a lack of insight and social judgment without any evidence of cognitive deficits or neurological signs. In addition, patients refuse to be treated. Since individuals with personality disorders respond negatively to treatments, researches on this subject is still inadequate, and clear data have not been obtained, yet. The view of therapists of personality disorders as "incurable" has a great effect on the insufficient data. Therefore, more studies and the underlying causes of a disorder need to be addressed in further years. Better research of the biological and environmental causes of personality disorders and more data about these reasons would help both to find clear treatment methods and to accelerate the treatment process.

\section{Declaration of conflicting interests}

The authors declared no conflicts of interest with respect to the authorship and/or publication of this article.

\section{Funding}

The authors received no financial support for the research and/or authorship of this article.

\section{REFERENCES}

1. National Institute for Mental Health for England. Personality Disorder: no Longer a Diagnosis of Exclusion. Policy Implementation Guidance for the Development of Services for People with Personality Disorder, Gateway Reference 1055. London: NIMH(E). 2003.

2. American Psychiatric Association. Diagnostic and statistical manual of mental disorders, 4th ed. Washington DC: American Psychiatric Association; 1994.

3. American Psychiatric Association. Diagnostic and statistical manual of mental disorders. 4th ed. Washington, DC: American Psychiatric Association; 2000.

4. American Psychiatric Association. Diagnostic and statistical manual of mental disorders: DSM-IV [Internet]. 4th ed. Washington (DC): American Psychiatric Association; 1994. p. 866. Available at: http://www. psychiatryonline.com/DSMPDF/dsm-iv.pdf.

5. American Psychiatric Association. Diagnostic and statistical manual of mental disorders (DSM-5). American Psychiatric Association. 2013. Available at: https://www.psychiatry.org/psychiatrists/practice/dsm

6. Thurston NS. Paranoid Personality Disorder. 1999. Available at: h ps://digitalcommons.georgefox.edu/ gscp_fac/286

7. Kaplan HI, Freedman AM, Sadock BJ, editors. Comprehensive Textbook of Psychiatry. Vol 2, 3rd ed. Baltimore: Williams \& Wilkins Co. 1980.

8. Crespi B, Read S, Salminen I, Hurd P. A genetic locus for paranoia. Biol Lett 2018;14:20170694.

9. Kety SS, Rosenthal D, Wender PH, Schulsinger F, Jacobsen B. Mental illness in the biological and adoptive families of adopted individuals who have become schizophrenic. Behav Genet 1976;6:219-25.

10. Winokur G. Familial psychopathology in delusional disorder. Compr Psychiatry 1985;26:241-8.

11. Webb CT, Levinson DF. Schizotypal and paranoid personality disorder in the relatives of patients with schizophrenia and affective disorders: a review. Schizophr Res 1993;11:81-92.

12. Kendler KS, McGuire M, Gruenberg AM, O'Hare A, Spellman M, Walsh D. The Roscommon Family Study. III. Schizophrenia-related personality disorders in relatives. Arch Gen Psychiatry 1993;50:781-8.

13. Freeman D, Garety PA, Bebbington PE, Smith B, Rollinson R, Fowler D, et al. Psychological 
investigation of the structure of paranoia in a nonclinical population. Br J Psychiatry 2005;186:427-35.

14. Munro A. Delusional (paranoid) disorders: etiologic and taxonomic considerations. I. The possible significance of organic brain factors in etiology of delusional disorders. Can J Psychiatry 1988;33:171-4.

15. Strome EM, Wheler GH, Higley JD, Loriaux DL, Suomi SJ, Doudet DJ. Intracerebroventricular corticotropin-releasing factor increases limbic glucose metabolism and has social context-dependent behavioral effects in nonhuman primates. Proc Natl Acad Sci U S A 2002;99:15749-54.

16. Turkat ID, Banks DS. Paranoid personality and its disorder. J Psychopathol Behav Assess 1987;9:295-304.

17. Weissman MM. The epidemiology of personality disorders: A 1990 update. Journal of Personality Disorders 1993;7:44-62.

18. Beck AT, Devis DD, Freeman A. Cognitive Therapy of Personality Disorders. New York: The Guilford Press; 1990.

19. Reichborn-Kjennerud T. The genetic epidemiology of personality disorders. Dialogues Clin Neurosci 2010;12:103-14.

20. Ward RK. Assessment and management of personality disorders. Am Fam Physician 2004;70:1505-12.

21. Johnson JG, Cohen P, Chen H, Kasen S, Brook JS. Parenting behaviors associated with risk for offspring personality disorder during adulthood. Arch Gen Psychiatry 2006;63:579-87.

22. Koponen S, Taiminen T, Portin R, Himanen L, Isoniemi $\mathrm{H}$, Heinonen $\mathrm{H}$, et al. Axis $\mathrm{I}$ and II psychiatric disorders after traumatic brain injury: a 30-year follow-up study. Am J Psychiatry 2002;159:1315-21.

23. Kandel J, Schwartz J, Jessell T. Principles of neural science, 4th ed. New York: McGraw Hill; 2000.

24. Esterberg ML, Goulding SM, Walker EF. Cluster A Personality Disorders: Schizotypal, Schizoid and Paranoid Personality Disorders in Childhood and Adolescence. J Psychopathol Behav Assess 2010;32:515-28.

25. Ünver B, Öner Ö, Yurtbaşı P. Sizotipal kişilik bozukluğu ile otizm spektrum bozukluklarının ayırıcı tanıs1: Bir olgu sunumu. Türk Psikiyatri Dergisi 2015;26:65-70.

26. Barneveld PS, Pieterse J, de Sonneville L, van Rijn S, Lahuis B, van Engeland H, et al. Overlap of autistic and schizotypal traits in adolescents with Autism Spectrum Disorders. Schizophr Res 2011;126:231-6.

27. Linscott RJ, van Os J. Systematic reviews of categorical versus continuum models in psychosis: evidence for discontinuous subpopulations underlying a psychometric continuum. Implications for DSMV, DSM-VI, and DSM-VII. Annu Rev Clin Psychol 2010;6:391-419.

28. American Psychiatric Association. Diagnostic and statistical manual of mental disorders-text revision. 4th ed. Washington, DC: American Psychiatric Association; 2000.

29. Linscott RJ, Morton SE; GROUP (Genetic Risk and Outcome of Psychosis) Investigators. The Latent Taxonicity of Schizotypy in Biological Siblings of Probands With Schizophrenia. Schizophr Bull 2018;44:922-32.

30. Barrantes-Vidal N, Grant P, Kwapil TR. The role of schizotypy in the study of the etiology of schizophrenia spectrum disorders. Schizophr Bull 2015;41 Suppl 2(Suppl 2):S408-16.

31. Ohi K, Hashimoto R, Nakazawa T, Okada T, Yasuda $\mathrm{Y}$, Yamamori $\mathrm{H}$, et al. The p250GAP gene is associated with risk for schizophrenia and schizotypal personality traits. PLoS One 2012;7:e35696.

32. Nordentoft M, Thorup A, Petersen L, Ohlenschlaeger $\mathrm{J}$, Melau M, Christensen TØ, et al. Transition rates from schizotypal disorder to psychotic disorder for first-contact patients included in the OPUS trial. A randomized clinical trial of integrated treatment and standard treatment. Schizophr Res 2006;83:29-40.

33. Kirchner SK, Roeh A, Nolden J, Hasan A. Diagnosis and treatment of schizotypal personality disorder: evidence from a systematic review. NPJ Schizophr 2018;4:20.

34. American Psychiatric Association. Diagnostic and statistical manual of mental disorders, fifth edition (DSM-5). Arlington, VA: American Psychiatric Publishing; 2013.

35. Beck AT, Davis DD, Freeman A. Cognitive Therapy of Personality Disorders. 3rd ed. New York: Guilford Press; 2015.

36. Lesch KP, Bengel D, Heils A, Sabol SZ, Greenberg $\mathrm{BD}$, Petri S, et al. Association of anxiety-related traits with a polymorphism in the serotonin transporter gene regulatory region. Science 1996;274:1527-31.

37. Roberts AL, Gilman SE, Fitzmaurice G, Decker MR, Koenen KC. Witness of intimate partner violence in childhood and perpetration of intimate partner violence in adulthood. Epidemiology 2010;21:809-18.

38. Kumari V, Gudjonsson GH, Raghuvanshi S, Barkataki I, Taylor P, Sumich A, et al. Reduced thalamic volume in men with antisocial personality disorder or schizophrenia and a history of serious violence and childhood abuse. Eur Psychiatry 2013;28:225-34.

39. Kumari V, Aasen I, Taylor P, Ffytche DH, Das M, Barkataki I, et al. Neural dysfunction and violence in schizophrenia: an fMRI investigation. Schizophr Res 2006;84:144-64.

40. Bertsch K, Grothe M, Prehn K, Vohs K, Berger C, Hauenstein $\mathrm{K}$, et al. Brain volumes differ between diagnostic groups of violent criminal offenders. Eur Arch Psychiatry Clin Neurosci 2013;263:593-606.

41. Foley DL, Eaves LJ, Wormley B, Silberg JL, Maes $\mathrm{HH}$, Kuhn J,et al. Childhood adversity, monoamine oxidase a genotype, and risk for conduct disorder. Arch Gen Psychiatry 2004;61:738-44. 
42. Archer T, Oscar-Berman M, Blum K, Gold M. Neurogenetics and Epigenetics in Impulsive Behaviour: Impact on Reward Circuitry. J Genet Syndr Gene Ther 2012;3:1000115.

43. Seo D, Patrick CJ, Kennealy PJ. Role of Serotonin and Dopamine System Interactions in the Neurobiology of Impulsive Aggression and its Comorbidity with other Clinical Disorders. Aggress Violent Behav 2008;13:383-95.

44. Bateman AW, Fonagy P. The structure of mentalization based treatment. In: Bateman AW, Fonagy P, editors. Mentalization-based treatment for borderline personality disorder. Oxford: Oxford University Press; 2006. p. 37-59.

45. McGauley G, Yakeley J, Williams A, Bateman A. Attachment, mentalization and antisocial personality disorder: The possible contribution of mentalizationbased treatment, European Journal of Psychotherapy \& Counselling 2011;13:371-93.

46. Yen S, Shea MT, Battle CL, Johnson DM, Zlotnick $\mathrm{C}$, Dolan-Sewell $\mathrm{R}$, et al. Traumatic exposure and posttraumatic stress disorder in borderline, schizotypal, avoidant, and obsessive-compulsive personality disorders: findings from the collaborative longitudinal personality disorders study. J Nerv Ment Dis 2002; $190: 510-8$.

47. Torgersen S, Lygren S, Oien PA, Skre I, Onstad $\mathrm{S}$, Edvardsen $\mathrm{J}$, et al. A twin study of personality disorders. Compr Psychiatry 2000;41:416-25.

48. Courtney-Seidler EA, Klein D, Miller AL. Borderline personality disorder in adolescents. Clin Psychol Sci Prac 2013;20:425-44.

49. Rinne T, de Kloet ER, Wouters L, Goekoop JG, DeRijk RH, van den Brink W. Hyperresponsiveness of hypothalamic-pituitary-adrenal axis to combined dexamethasone/corticotropin-releasing hormone challenge in female borderline personality disorder subjects with a history of sustained childhood abuse. Biol Psychiatry 2002;52:1102-12.

50. Kring AM, Johnson SL, Davison G, Neale J. Anormal Psikolojisi/Psikopatoloji. İstanbul: Nobel Akademik Yayıncilik; 2007.

51. Paris J. Suicidality in Borderline Personality Disorder. Medicina (Kaunas) 2019;55:223.

52. Kellett S. A time series evaluation of the treatment of histrionic personality disorder with cognitive analytic therapy. Psychol Psychother 2007;80:389-405.

53. Novais F, Araújo A, Godinho P. Historical roots of histrionic personality disorder. Front Psychol 2015;6:1463.

54. Morrison J. Histrionic personality disorder in women with somatization disorder. Psychosomatics 1989;30:433-7.

55. Sulz S. Hysterie I. Hysteria I. Histrionic personality disorder. A psychotherapeutic challenge. Nervenarzt 2010;81:879-87.

56. Nestadt G, Romanoski AJ, Chahal R, Merchant A, Folstein MF, Gruenberg EM, et al. An epidemiological study of histrionic personality disorder. Psychol Med 1990;20:413-22.

57. Masterson JF. A Therapist's Guide to the Personality Disorders: The Masterson Approach: A Handbook and Workbook. Phoenix, Az.: Zeig, Tucker, \& Theisen Inv 2004.

58. Otway LJ, Vignoles VL. Narcissism and childhood recollections: a quantitative test of psychoanalytic predictions. Pers Soc Psychol Bull 2006;32:104-16.

59. Jang KL, Livesley WJ, Vernon PA, Jackson DN. Heritability of personality disorder traits: a twin study. Acta Psychiatr Scand 1996;94:438-44.

60. Groopman LC, Cooper AM. Narcissistic personality disorder. In: Gabbard GO, editor. Treatments of Psychiatric Disorders. 2nd ed. Washington, DC: American Psychiatric Press Inc; 1995 p. 2327-43.

61. Dehrkoop K. An Overview of Avoidant Personality Disorder. All eses, Dissertations, and Other Capstone Projects; 2012. Available at: https://cornerstone.lib. mnsu.edu/etds/551/

62. Gjerde LC, Czajkowski N, Røysamb E, Orstavik $\mathrm{RE}$, Knudsen GP, Ostby $\mathrm{K}$, et al. The heritability of avoidant and dependent personality disorder assessed by personal interview and questionnaire. Acta Psychiatr Scand 2012;126:448-57.

63. Joyce PR, Rogers GR, Miller AL, Mulder RT, Luty SE, Kennedy MA. Polymorphisms of DRD4 and DRD3 and risk of avoidant and obsessive personality traits and disorders. Psychiatry Res 2003;119:1-10.

64. Sevinçok L, Dereboy F, Dereboy Ç. Çekingen kişilik bozukluğunun klinik özellikleri ve tedavisi. Klinik Psikiyatri 1998;1:22-6.

65. Isomura K, Boman M, Rück C, Serlachius E, Larsson $\mathrm{H}$, Lichtenstein $\mathrm{P}$, et al. Population-based, multigenerational family clustering study of social anxiety disorder and avoidant personality disorder. Psychol Med 2015;45:1581-9.

66. Bornstein RF. The dependent personality: developmental, social, and clinical perspectives. Psychol Bull 1992;112:3-23.

67. Sperry L. Handbook of diagnosis and treatment of DSM-IV-TR personality disorders. 2nd ed. New York: Brunner-Routledge; 2003.

68. Murphy B, Warin C. Understanding obsessivecompulsive disorder (OCD); 2013.

69. Taylor S. Molecular genetics of obsessive-compulsive disorder: a comprehensive meta-analysis of genetic association studies. Mol Psychiatry 2013;18:799-805.

70. Shugart YY, Samuels J, Willour VL, Grados MA, Greenberg BD, Knowles JA, et al. Genomewide linkage scan for obsessive-compulsive disorder: evidence for susceptibility loci on chromosomes 3q, 7p, 1q, 15q, and 6q. Mol Psychiatry 2006;11:763-70.

71. Jaffee SR, Price TS. Gene-environment correlations: a review of the evidence and implications for prevention of mental illness. Mol Psychiatry 2007;12:432-42. 